\title{
Adolescents and Teachers as Partners in a School-Based Research Project to Increase Physical Activity Opportunities in a Rural Community
}

\author{
James Rye \\ Nancy O'Hara Tompkins \\ West Virginia University \\ Darlene McClure \\ Jacqueline Aleshire \\ Scott High School, \\ Madison, $W V$
}

\begin{abstract}
Schools are an important resource in combating the physical inactivity and obesity epidemics in rural economically depressed areas. Through a University-community partnership, teachers and adolescents in a rural West Virginia county with one of the highest obesity rates in the state developed a school-based research intervention to increase physical activity opportunities. The intervention included walking routes, educational sessions, and pedometers. A survey about barriers to physical activity revealed that "lack of willpower" was a barrier of concern among program participants (mostly school employees) and had a statistically significant $(p=.0033)$ pre to post mean score decrease during the year two offering. Focus groups with the adolescent researchers revealed that pedometers may facilitate maintenance of physical activity and a broader community impact. Focus group dialogue combined with teacher-researcher perspectives suggested that the adolescents changed their weight control paradigm from "dieting" to include the critical role of energy expenditure.
\end{abstract}

The United States is experiencing an obesity epidemic in youth and adults (Hill, Wyatt, Reed, \& Peters, 2003). The proportion of overweight adolescents has increased more than three-fold in the past 25 years and approximately 31\% of adults are obese (Lavizzo-Mourey \& McGinnis, 2003; Lee, Wechsler, \& Balling, 2006). The severity of the problem is greater in rural than urban areas and in Appalachia (Gamm, Hutchison, Dabney, \& Dorsey, 2003; Halverson, Ma, Harner, Hanham, \& Braham, 2004). A recent national study found that children living in rural areas are $25 \%$ more likely to be overweight or obese than their metropolitan peers (Lutfiyya, Lipsky, Wisdom-Behounek, \& Inpanbutr-Martinkus, 2007). Studies also have found that rural adults are less likely to be physically active than their urban and suburban counterparts (Patterson, Moore, Probst, \& Shinogle, 2004).

Authorities have speculated that obesity is a symptom of more pervasive problems in our society, such as a built environment that removes retail outlets and schools from the center of communities, lacks sidewalks and bike paths, and forces automobile dependence (Frumkin, Frank, \& Jackson, 2003; Jackson, 2003; Lavizzo-Mourey \& McGinnis, 2003). This is particularly true in rural and low socioeconomic communities where there is a shortage of safe places to be physically active and/or where a sizeable proportion of residents lack financial resources to join fitness facilities (Gamm et al., 2003; Powell, Slater, Chaloupka, \& Harper, 2006).

The physical activity research project described in this paper was carried out in West Virginia, which lies entirely in Appalachia and ranks third highest among all states on percentage of population classified as rural (Rural population, 2002). West Virginia also is among those states with the highest adult prevalence of obesity (Behavioral Risk Factor Surveillance System, n.d.) and has the highest percent of residents with a chronic disease (DeVol \& Bedroussian, 2007). The rural community involved in this project mirrors the conditions presented above: It has a mountainous topography and transportation infrastructure of narrow roads that lack pedestrian and bicycle accommodations, ranks very high among all counties in West Virginia for adulthood obesity (West Virginia Department of Health \& Human Services, n.d.), and has the $13^{\text {th }}$ highest poverty rate (ages 18-64) of all 55 counties in West Virginia (The Annie E. Casey Foundation, n.d.).

Universities and communities should collaborate toward the prevention and mitigation of health problems such as obesity and physical inactivity, and these collaborative efforts can involve schools and surrounding grounds as important community resources (Adams, Miller-Korth, \& Brown, 2004; Heath, 2003; Hubsmith, 2006; Institute of Medicine [IOH], 2005; Rye, O'Hara Tompkins, Eck, \& Neal, 2008; U.S. Department of Health and Human Services [USDHHS], 2001). Such efforts should embed an ecological approach (emphasizes the interdependence of individuals with their social and physical environments) and be guided by principles of community-based participatory research: a cyclical process characterized by mutual respect and community involvement in design through dissemination of the research (Adams et al., 2004; Green \& Kreuter, 1999; Lantz, Viruell-Fuentes, Israel, Softley, \& Guzman, 2001). Lengerich et al. (2006) have contended that a community- 
based participatory approach is "possibly essential” (p. 1) to reduce the chronic disease burden in Appalachian communities. Within this context, adolescents can be an important human resource in helping communities to address and resolve environmental and health-related problems (Checkoway et al., 2003). Youth as partners to address community issues is a budding field; additional benefits to youth include enhancing their competence and promoting a paradigm shift among adults from youth as a liability to youth as an asset (Camino, 2005; Checkoway et al., 2003; Horsch, Little, Smith, Goodyear, Harris, 2002; London, Zimmerman, Erbstein, 2003). This paper describes a community-based research project in which secondary teachers and high school students endeavored to increase physical activity opportunities for a subset of community members.

\section{Background}

This particular project was one of six different physical activity interventions conceived and carried out by university researchers, teachers and high school students participating in the Health Sciences and Technology Academy (HSTA) (O’Hara Tompkins, Rye, Zizzi, \& Vitullo, 2005). HSTA provides science and math enrichment to underrepresented youth and encourages them to pursue postsecondary education in the health sciences as well as remain in West Virginia as health care providers (Rye, 1998; Rye \& Chester, 1999). Especially relevant to these projects is the additional HSTA goal of fostering a "wellness" disposition among HSTA students as future health care practitioners. These projects were part of a larger national movement in which academicians and communities are "Learning to work together" toward effective research partnerships (Adams et al., 2004, p. 15). O’Hara Tompkins et al. (2005) described the professional development and support provided to teachers to develop and carry out the six projects, including the Institutional Review Board (IRB) approval to conduct human subject research. To facilitate a community-based research approach, the teachers and students were encouraged to identify their target audience, develop program components that would suit that audience, and set forth a timeline.

The project described herein was implemented during two consecutive years by two secondary teachers with primary responsibilities in health and science instruction and their HSTA students (20 in the first and 22 in the second year, spread across grades 9-12). Local health care practitioners and university faculty in the health and science education fields assisted with the implementation. The students were motivated by the high obesity ranking of their county among all counties in the state. Prior to developing their project, the students reviewed materials and/or attended sessions by local health care professionals about cardiovascular disease and pediatric diabetes. They researched statistics related to obesity and also became aware of the lack of local [safe] places to exercise. The teachers and students proposed a project that they hoped would encourage participants to "get on their feet" through the use of pedometers, indoor and outdoor walking trails, and group games. Students helped to develop a timeline and evaluation design and associated research questions such as: Will the participants increase their average daily step count over the period of the program? Do the educational sessions provided by the program reduce participants' perceptions about barriers to exercise? Students recruited participants, helped organize and conduct educational and physical activity sessions, collected data, and presented their program at two statewide HSTA symposiums.

\section{Methods}

\section{Participants}

Participants for the program were recruited by word of mouth in and outside of the school and at a local health fair conducted by area health care practitioners for the first year of the project; and via word of mouth and a flyer the second year. During year one, five HSTA students who helped to deliver the program also participated in the program: Their data were removed from the analysis of participant outcomes reported in the findings below, leaving 16 participants (all adults, 3 males, 13 females). Year two had 15 adult participants: 2 males and 13 females, and three were "repeaters" from year one. During each year, the majority of participants were school district employees (some being faculty and staff in the school where the research was based); the remainder were comprised of parents and other community members. Informed consent was procured at or before the first program session.

Participants for the focus groups were the HSTA students who helped to deliver the program. Informed consent from parents and assent from students were obtained prior to the focus groups. Twelve students participated in the focus groups for year one and 5 in year two.

\section{Procedures}

The procedures relative to conducting the program were comprised of data collection from participants to determine baseline (pre) and end-of-program (post) measurements, the provision of seminars and physical activity opportunities/sessions, and data analysis. The time lapse between pre and post measurements was 2 to 3 months. The teachers and students were encouraged to involve local health care professionals as partners and providers, which would expose the students to health care fields, help to insure quality/technical accuracy of the program, and enhance visibility of the program.

1. Data Collection. Data collection for this project was primarily geared toward giving the student researchers hands-on experience in collecting, analyzing and 
interpreting data about their project. A variety of measures were used to expose students to different measurement methods and to assure that all students would have something to present at the HSTA symposium. Three questionnaires assessing psychosocial factors associated with physical activity were used: Barriers to Physical Activity (U.S. Department of Health and Human Services, 1999) and Confidence/Self-efficacy and Outcomes Expectations for Exercise (Marcus \& Forsyth, 2003). These questionnaires could be analyzed by total score and by subscale scores. Participants also were asked to keep a step log to ascertain their baseline step count for the one-week period after orientation to the pedometers (Accusplit ${ }^{\mathrm{TM}}$ Eagle $^{\circledR}$ [AE] 170, www.accusplit.com) that they were given at the first seminar; step logs were completed mid way through and at program completion by year two participants only. Additionally, participants were asked to complete the Physical Activity Readiness Questionnaire (PAR-Q) (n.d.) and to consult with their physician before increasing their physical activity level if their response was "yes” to any of the questions.

2. Seminars. Educational sessions that were provided during one or both years of the program included nutrition (especially dietary fat and kcal) and low calorie cooking, stress and its effects on weight loss, exercise and its effects on fat metabolism and the heart, flexibility/stretching, and orientation to pedometers and indoor walking routes at the school. Most of the presentations were provided by local health care professionals (e.g., dietitian) and interns where the HSTA students assisted in setting up and participating in demonstrations; students played a more active role in the nutrition/low calorie cooking session and the major role in pedometer orientation of participants (Figure 1), which included determining stride length and programming the pedometers with stride length as well as body weight data. Participants were encouraged to work toward a 10,000 steps per day goal and provided with a step count log.

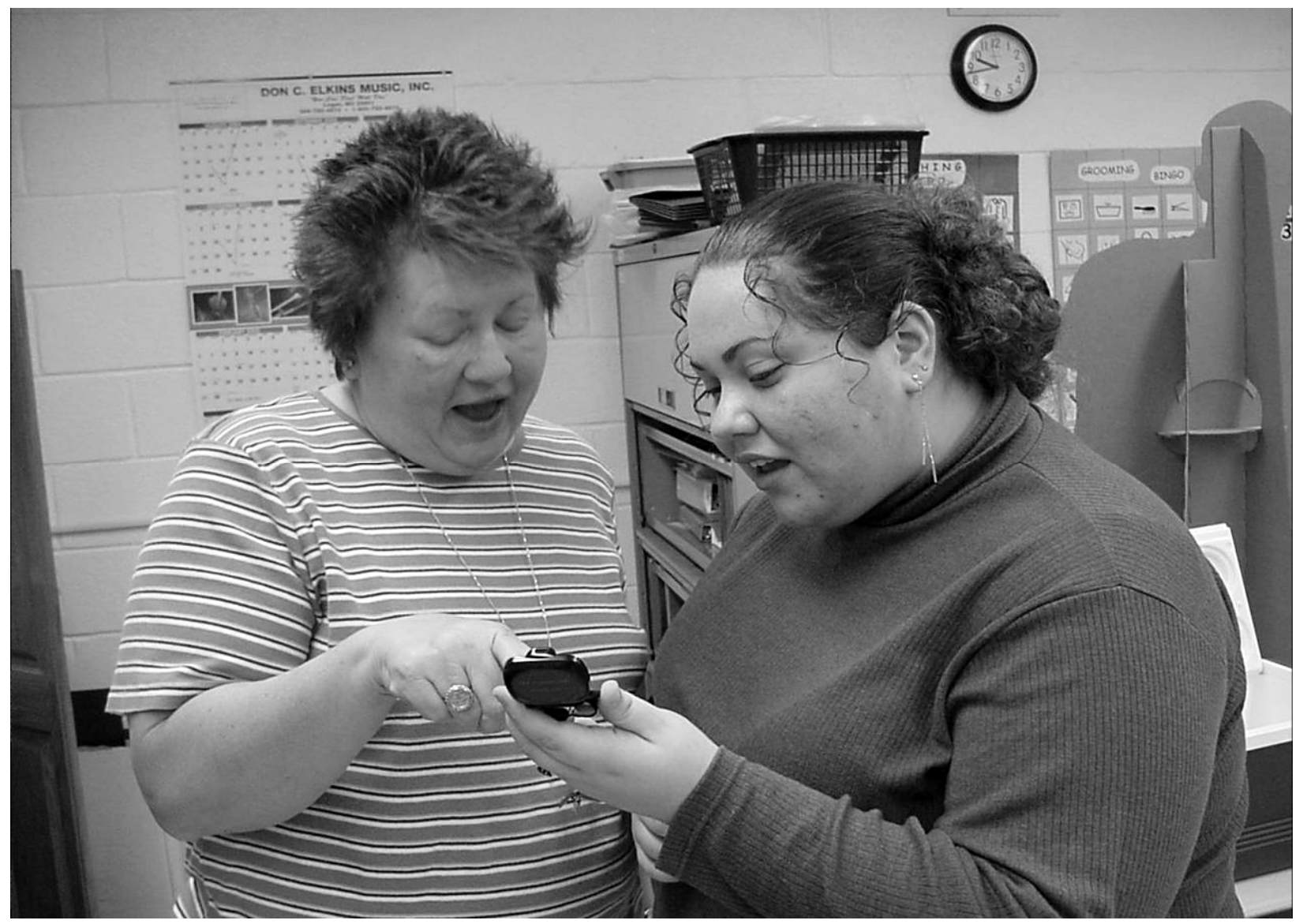

Figure 1. Student providing pedometer orientation to program participant.

3. Physical Activity Opportunities. Students established three indoor walking trails in the school (Figure 2), which they labeled as easy, moderate, and hard based on length and the degree to which the stairwells were incorporated. The community also had an existing 2.5 mile outdoor walking trail located one-quarter mile from the school. Students organized several walking activities/sessions at the community trail as well as the school outdoor track (around the football field) and indoor trails. During year one, eight evening sessions of volleyball and basketball games were 
offered by the students and teachers as well as one session on "Games Grandpa and Grandma Used to Play” (e.g., hop scotch, hula hoop). During year two, students focused the program more on walking, including the establishment of walking groups.

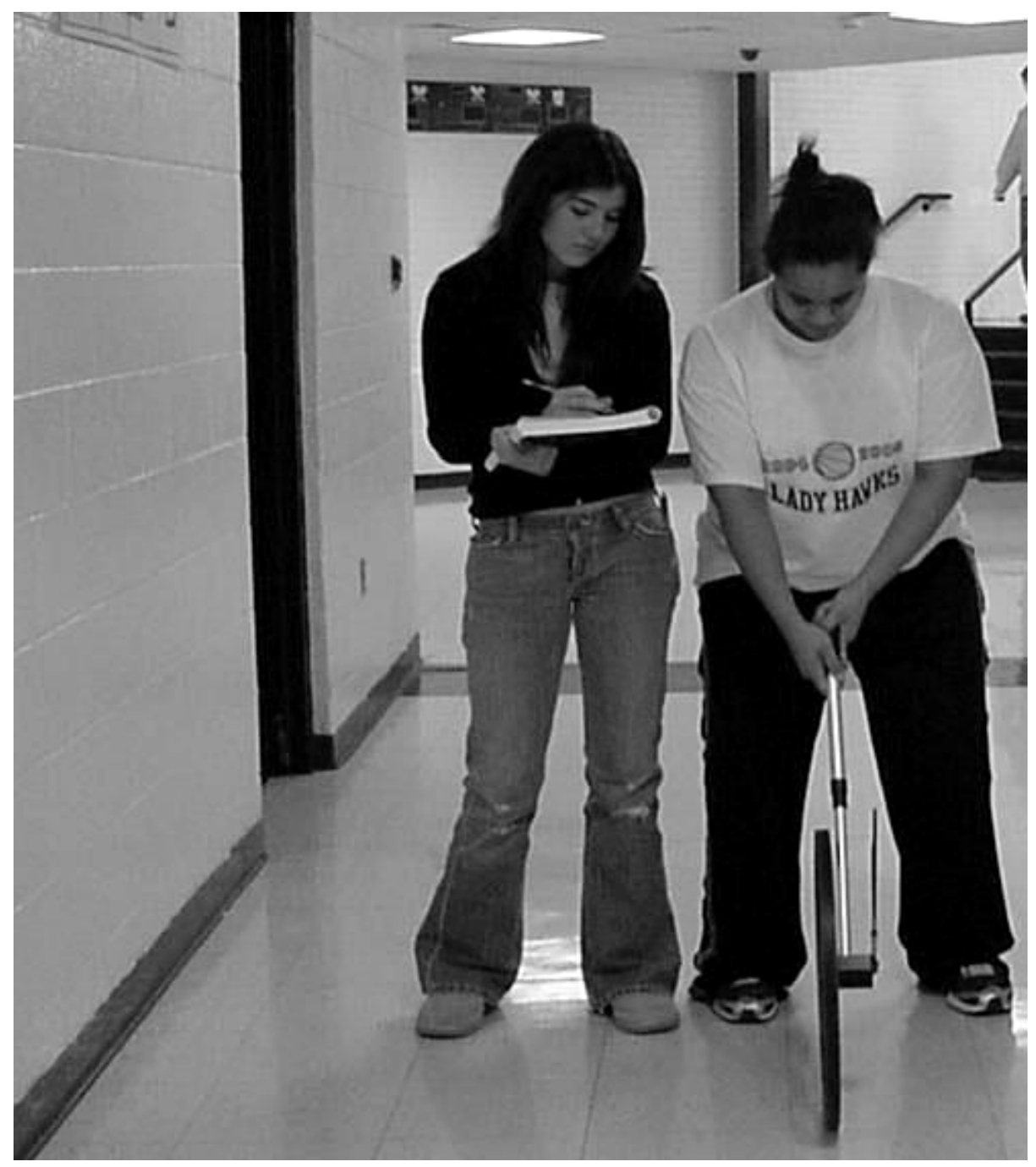

Figure 2. Students marking off indoor walking trail.

4. Data Analysis. Students entered the data into Microsoft Excel ${ }^{\circledR}$ templates; data entry was checked (quality assurance) and analyzed by university faculty. Data analysis was limited to descriptive statistics and paired 2-sample for means $t$-tests (one-tailed) to determine the degree to which pre to post perceived barriers (total and subscales) to exercise decreased and weekly average step count, selfefficacy, and outcome expectations increased.

Focus groups were conducted with the students near the completion of their project each year to ascertain their perceptions of the project. Two focus groups were held during year one (to obtain input of as many students as possible) and one focus group during year two. Each focus group was moderated by the same university faculty researcher and occurred at the school where the project was conducted. The focus group questions were grounded in the ecological view of health behavior and most specifically, reciprocal determinism, which emphasizes the critical role of the environment (Green \& Kreuter, 1999). All 3 focus groups queried students about their perceptions of the following: local barriers to physical activity; highlights, limitations, and suggested changes for their project; and impact on participants and the broader community. In the year two focus group, students also were asked to compare years one and two of the project. The focus groups were audio-taped and transcribed, and they were analyzed by the 
focus group moderator for themes using Ethnograph ${ }^{\circledR}$ (Version 5.0, Qualis Research Associates 1998).

\section{Principal Findings}

\section{Program Participant Outcomes}

During year one, 50\% (8 individuals) of the participants increased (pre to post) and 50\% decreased their total score on the barriers to exercise questionnaire. During year two, 73\% (11 individuals) of the participants decreased their barriers total score whereas 3 remained the same and only 1 increased; the mean decrease $(M=23.73$ [SD $=10.70]$ to $12.67[S D=8.55])$ was statistically significant $(p=.0009)$.
Table 1 provides descriptive statistics on the pre and post barriers total and seven subscale mean scores for years one and two. Lack of willpower was the only measure that had a pre score $\geq 5$ (signifying an "important obstacle" to overcome). Lack of willpower and lack of energy (the second highest pre score for each year) had the largest raw score decreases in each year. Applying the Bonferroni Correction for performing multiple t-tests $(.05 / 11=.0045)$ on the same sample, the pre to post decreases in the year two mean scores were statistically significant for total barriers $(p=.0009)$ as well as lack of energy $(p=.0007)$, time $(p=.0024)$, and willpower $(p=.0033)$ (Weisstein, n.d.).

Table 1.

Mean (M) and Standard Deviation (SD) of Total and Subscale Scores on Exercise Barriers Questionnaire

\begin{tabular}{|c|c|c|c|c|c|c|c|c|}
\hline & \multicolumn{4}{|c|}{$\frac{\text { Year 1 }}{(n=16)}$} & \multicolumn{4}{|c|}{$\frac{\text { Year } 2}{(n=15)}$} \\
\hline & \multicolumn{2}{|c|}{ Pre } & \multicolumn{2}{|c|}{ Post } & \multicolumn{2}{|c|}{ Pre } & \multicolumn{2}{|c|}{ Post } \\
\hline & $M$ & $S D$ & $M$ & $S D$ & $M$ & $S D$ & $M$ & $S D$ \\
\hline total & 21.94 & 9.67 & 16.38 & 8.52 & 23.73 & $\begin{array}{c}10.7 \\
0\end{array}$ & $\begin{array}{c}12.6 \\
7\end{array}$ & 8.55 \\
\hline lack time ${ }^{a}$ & 3.56 & 1.90 & 2.69 & 2.02 & 4.07 & 1.71 & 2.33 & 2.38 \\
\hline social & 3.56 & 2.03 & 2.56 & 1.50 & 3.47 & 1.64 & 2.47 & 1.77 \\
\hline \multicolumn{9}{|l|}{ influence $^{\mathrm{a}}$} \\
\hline lack energy ${ }^{a}$ & 4.56 & 1.63 & 3.44 & 2.10 & 4.73 & 2.37 & 2.60 & 2.72 \\
\hline lack willpower ${ }^{\mathrm{a}}$ & 5.38 & 2.92 & 4.31 & 2.65 & 6.00 & 2.39 & 3.27 & 2.46 \\
\hline fear injury ${ }^{a}$ & 1.19 & 1.38 & .63 & .96 & 1.53 & 1.77 & .20 & .56 \\
\hline lack skill ${ }^{\mathrm{a}}$ & 1.00 & 2.16 & .94 & 1.53 & 1.13 & 1.85 & .33 & .90 \\
\hline lack resources ${ }^{\mathrm{a}}$ & 2.69 & 2.15 & 1.81 & 2.46 & 2.8 & 2.68 & 1.47 & 1.68 \\
\hline
\end{tabular}

aSubscale. Score $\geq 5$ indicates an "important obstacle" to overcome

No significant changes (pre to post) were found in selfefficacy or outcome expectations. Year two participants had a statistically significant increase $(p=.0009)$ in pre to post average daily step count: $M=6600(S D=3017)$ to 9132 $(S D=2977)$.

\section{HSTA Students' Perceptions}

In regards to why people in their communities do not get sufficient physical activity, during both years students spoke to lack of place, e.g., "There's really no where for 'em to go.” Another barrier cited both years was related to education level or knowledge, e.g., "they don't really know how to get out and be active." Additional reasons cited by students during year one spoke to being lazy, lack of time, and too much screen time.

In discussing aspects of their project, for both years students perceived the need to do more sessions/activities and have more participants. Students during year one also voiced interest in increasing the duration of the program, 
e.g., "Like we could keep goin' instead of having to quit after the project" and "Start earlier in the year." It also was apparent that during year two "more participants" could have been realized if joining "late” had been an option:

Moderator: You guys have been doing this for a couple of years. Do you have any evidence that people other than your participants actually were affected by your project?

Student: Yeah, I think so. Cause like we, a, surveyed like teachers around and stuff and like other teachers were wantin' to do it.

Student: Like, halfway through the project they tried to come to us and ask us.

Student: You know, we wanna be in your project and we said...it's too late.

Students remarked also for year two that "a lot of parents" wanted to join late: "Once some of the parents signed up I guess they contacted other people and let 'em know and by the time they got to us it was too late.” Related to this was the comment that it was easier to get people involved in the program during year two due, in part, to participants from year one spreading the word: "Some people, they don't like to try new things, they wait 'til other people try it and then they probably talk about how wonderful it was and so they said, Oh, I wanna sign up."

The theme of mental health emerged from the focus groups during year one. Students remarked about a relationship between obesity and depression. They inferred that depression negatively impacted feelings of self worth and that physical activity and weight loss boosted participants' self-confidence.

Pedometers were cited during both years as being fun or exciting. They also were tied to potential long term or broader community impact of the project:

Hopefully, if their pedometers are still working, that they'll keep on using 'em and maybe...spread to other people. That it's one way to see how active you're being in your day. Maybe more people in the county will get pedometers and, you know, start bein' more active.

For year two, pedometer utilization was tied to being competitive: "A lot of them tried to compete with their steps, like um, comparing 'em to each other and trying to get more.”

Program results or outcomes appeared to be more important to students during year two, e.g., "I like the results that it changed from the beginning to the end. You know, how much people were walking and getting out there and doing stuff." This perception likely was due in part to more complete data collection of the step counts during year two:
"We didn't analyze their steps last year....But this time we actually went in and, you know, got results." One student remarked that "We wanted to continue it [the program] next year....to see the outcome of next years'." In asking students to contrast both years, they surfaced only ways that the program was better the second year, including that it was more organized and that there was more flexibility in the physical activity portion of the program due to the emphasis on walking as opposed to group/team games, e.g., "They didn't necessarily have to show up at a certain time.... They could walk on their own, but they also could walk together. You know, it was their choice.” One student also spoke to the increased student researcher commitment during year two: "The people [HSTA students] that came in were more active with wantin' to be a part of the project instead of, you know, sittin' back and lettin' everybody else do the work.”

Additional perceptions of the students who participated in the year one focus groups are presented in a separate paper that combines findings from focus groups conducted with students who carried out all six of the HSTA physical activity projects (Rye, Vitullo, O’Hara Tompkins, \& Zizzi, 2006).

\section{Discussion}

The rigor of the research reported herein is limited by the absence of a control group, small samples of convenience, and a relatively short duration of the intervention. However, this was participatory communitybased research, and this particular project was far beyond the scope of what normally is undertaken by HSTA students. Youth efforts such as these to improve community health are rare and should be considered "exceptional," and it is remarkable that they were inspired to continue their project for a second year (Checkoway, 2003; McCormackBrown, Forthofer, Bryant et al., 2001). In fact, all of the HSTA students chose to be involved in delivering the program (as opposed to doing a different project) the second year. From the year two focus group, the value of revising their program based on initial experiences, and reoffering that program a second year, was apparent: Students felt more organized and believed that the program improved due to a more flexible approach to physical activity. Students developed heightened interest in program outcomes, and program features were viewed as salient by parents and teachers as evidenced by their interest in joining the program "in progress."

An independent samples $t$-test (two tailed, assuming unequal variances) revealed no significant difference ( $p=$ .629) between the year one and two barriers questionnaire total mean pre scores (Table 1). However, on the post measure, $50 \%$ of the year one participants actually increased their score (i.e., perceived greater barriers than at the beginning of the program) as opposed to only $7 \%$ of year two participants. Perhaps this was due in part to the increased attention on walking and greater flexibility of the 
physical activity component of the program during year two. These findings may also reflect an improvement in the program based on the year one experience and increased commitment of the students. Additionally, these findings coupled with the students' perceptions from the focus groups about year two validate the importance of the cyclical process "principle" of community-based research.

Physical activity is a critical component in weight control. In response to "What did you hope to accomplish" during the year one focus group, one student remarked: "Just to show people that physical...I mean just activity, just exercise, would be the best way to lose weight. And you can still eat what you want, but just don't eat as much as you normally do." The students elaborated on the latter by discussing the emphasis their program placed on portion size and participant reaction to food models illustrating the suggested portion sizes: "They were shocked. I mean, like, their eyes got really big." From the perspective of the two teachers who partnered with the student researchers to conduct this project, the students' prior understandings were limited to the idea that dieting is the only way to lose weight. An important impact of the project on these students was the enlightened understanding that increasing physical activity also was a means to weight loss/control, and doing so allowed one to still have some of the foods that they previously thought they had to give up. The students realized that they could change lifestyles-just a few factors - which could make a real difference.

Using the preliminary categorical indices proposed by Tudor-Locke and Bassett (2004), the year two participants' (almost all females) increased their mean daily step count from "low active" (5000-7499) at baseline (6600) to "somewhat active" (7500-9999) by program completion (9132). These findings are similar to a study of women who were given a " 10,000 steps per day" goal to achieve over a short-term (3-week) intervention period (baseline $=6,363$, week $3=8839$ ) (Sidman, Corbin, LeMasurier, 2004). In the study that is the focus of this paper, no follow-up measures were obtained to assess participant adherence to wearing the pedometer or maintenance of increased step count. Such measures would have added to the value of this study and could be contrasted with those reported by Sidman et al. (2004) where self-reported follow-up data suggested poor adherence and that most participants did not maintain their step count level achieved during the study. Importantly, pedometers were viewed by the students as a salient program feature and believed important to participant maintenance of increased physical activity levels.

Additional project impacts reported by the teachers who helped to facilitate this research speak to the broader potential of schools in mitigating the physical inactivity and obesity epidemics. From their perspective, energy balance was the most important concept learned-that you need to make sure you are expending as much energy (for weight maintenance), if not more (for weight loss), than you are ingesting. From witnessing the interest of the HSTA students in the topic of nutrition, one of the teachers has added a small nutrition unit to her anatomy and physiology course. The other teacher's whole outlook changed relative to the classroom in realizing that students could be truly interested in taking better care of their bodies and future health if taught to do so. Students today are thinking about "getting old" and classroom instruction needs to respond accordingly. During the project, friends of HSTA students came in from neighboring towns to use the community walking trail (humorously referred to as "the fat track"). Teachers report that many people continue to use the walking track, including present day HSTA students and former participants of the project. One of the teachers was involved in writing a grant proposal for a community infrastructure improvement to connect via a walking bridge an adjacent town to this community walking trail. Unfortunately, the grant proposal was not funded, but the teacher has continued her efforts to find funding for the walking trail. Current and past HSTA students have continued to contact the teachers about information and resources related to the project, such as step logs, determining stride length, steps to mile conversion charts, and distances of the in-school walking route. Teachers who participated in the project continue to walk daily and new teachers have joined the walking groups that were initiated through this project. Both of the teachers' involvement in this project has had a substantial impact on the school district wellness policy, currently being implemented through a grant awarded by the state. Through their voice as members of the wellness committee, the policy includes a major emphasis on activity/movement in the school day routine.

\section{Conclusions}

University-community collaborations that engage secondary health and science teachers and students as partners can result in school-based health promotion programming for school employees that contain features "strongly recommended" by the Task Force for Community Preventive Services: individual behavior change (e.g., goal setting for step counts), social support (e.g., walking groups), and creating/enhancing access to physical activity (e.g., indoor walking trails) (Heath, 2003). To maximize participation, such programming should have multiple "start" dates to allow employees to join at various times during the academic year. Importantly, employee wellness programming also is an evidence-based strategy that schools should implement towards the control of childhood obesity (Lee, Wechsler \& Balling, 2006). Additionally, grass-roots programs such as these can inform the wellness policy that all schools needed to implement in the 2006-2007 academic year in order to continue receiving federal assistance for their foodservice program (U.S. Department of Agriculture, 2004). 
Rural communities are facing huge challenges related to both the burden of chronic disease consequent to unhealthy lifestyles and youth out migration/brain drain due to lack of meaningful opportunities (Bauch, 2001). Our findings support the contentions of Tolman and Pittman (2001): It is a myth that youth lack the motivation and skills to "make a difference" in their communities. Combined with sustained interest by the HSTA teachers who were co-researchers with the students, this project was an excellent example of Camino's (2005) “collective construct” (p. 84) about youthadult partnerships: adults and adolescents working together on issues of mutual concern. Such efforts are especially noteworthy in rural areas because they bolster meaningful extracurricular opportunities for youth as well as physical activity resources for the community.

Approval to conduct this research was provided by the West Virginia University Institutional Review Board for the Protection of Human Subjects Protocols No. 16041 and 15632. A poster based on this paper was presented at the 135th Annual Meeting \& Exposition of the American Public Health Association, Washington, DC, November, 2007. The authors are very appreciative of the HSTA students for their continued efforts in addressing important public health problems in their community. The project described was supported by funds from the Centers for Disease Control and Prevention (CDC) Grant Award No. H75CCH322130-02 through the West Virginia University Prevention Research Center and by Grant Number 2R25RR1232904 from the National Center for Research Resources (NCRR), a component of the National Institutes of Health (NIH). Its contents are solely the responsibility of the authors and do not necessarily represent the official views of CDC, NCRR, or NIH.

\section{References}

Adams, A., Miller-Korth, N., \& Brown, D. (2004). Learning to work together: developing academic and community research partnerships. Wisconsin Medical Journal, 103(2), 15-19.

Bauch, P.A. (2001). School-community partnerships in rural schools: leadership, renewal, and a sense of place. Peabody Journal of Education, 76(2), 204-221.

Behavioral Risk Factor Surveillance System (n.d.). Prevalence data. Overweight and obesity- 2007 (BMI). Weight classification by Body Mass Index (BMI). Atlanta, GA: Centers for Disease Control and Prevention. Retrieved August 28, 2008, from http://apps.nccd.cdc.gov/BRFSS/list.asp?cat=OB\&yr=2 $\underline{007 \& q k e y=4409 \& \text { state }=\text { All }}$
Camino, L. (2005). Pitfalls and promising practices of youth-adult partnerships: an evaluator's reflections. Journal of Community Psychology, 33, 75-85.

Checkoway, B., Richards-Schuster, K., Abdullah, S., Aragon, M., Facio, E., Figueroa, L. et al., (2003). Young people as competent citizens. Community Development Journal, 38, 298-309. Retrieved March 31, 2006, from EBSCOhost.

DeVol, R., \& Bedroussian, A. (2007). An unhealthy America: the economic burden of chronic disease. Milken Institute, October 2007. Retrieved September 1, 2008, from http://www.milkeninstitute.org

Frumkin, H., Frank, L., \& Jackson, R. (2004). Urban sprawl and public health. Washington DC: Island Press.

Gamm, L., Hutchison, L., Dabney, B., \& Dorsey, A., (Eds.). (2003). Rural healthy people 2010: a companion document to healthy people 2010, (Vol. 1). College Station, Texas: The Texas A\&M University System Health Science Center, School of Rural Public Health, Southwest Rural Health Research Center. Retrieved December 29, 2006, from http://www.srph.tamhsc.edu/centers/rhp2010/publicatio ns.htm

Green, L. W., \& Kreuter, M. W. (1999). Health promotion planning. Mountain View, CA: Mayfield Publishing Company.

Halverson, J., Ma, L., Harner, E., Hanham, R., Braham, V. (2004). Adult obesity in Appalachia: an atlas of geographic disparities. Morgantown, WV: Office of Social Environment and Health Research, West Virginia University.

Heath, G. (2003). Increasing physical activity in communities: What really works? President's Council on Physical Fitness and Sports Research Digest; Series 4: No. 4. Retrieved July 6, 2006, from http://fitness.gov/Reading_Room/Digests/DigestDecember2003.pdf

Hill, J., Wyatt, H., Reed, G., Peters, J. (2003). Obesity and the environment: Where do we go from here? Science, 299, 853-855.

Horsch, K., Little, P., Smith, J., Goodyear, L., \& Harris, E. (2002). Youth involvement in evaluation and research. Harvard Family Research Project Issues and Opportunities in Out-Of-School Time Evaluation. 1, 18. Retrieved March 26, 2006, from:

http://www.gse.harvard.edu/hfrp/projects/afterschool/re sources/issuebrief1.html

Hubsmith, D. A. (2006). Safe routes to school in the United States. Children, Youth and Environments [serial online]. 16, 168-190. Retrieved August 27, 2008, from http://www.colorado.edu/journals/cye/16_1/16_1_11_ SafeRoutestoSchool.pdf

Institute of Medicine. (2005). Preventing childhood obesity: health in the balance. Washington, D.C.: National Academy Press. 
Jackson, R. J. (2003). The Impact of the built environment on health: An emerging field. American Journal of Public Health, 93, 1382-1383.

Lantz, P., Viruell-Fuentes, E., Israel, B., Softley, D., \& Guzman, R. (2001). Can communities and academia work together on public health research? Evaluation results from a community-based participatory research partnership in Detroit. Journal of Urban Health: Bulletin of the New York Academy of Medicine, 78, 495-507.

Lavizzo-Mourey, R. \& McGinnis, J. M. (2003). Making the case for active living communities. American Journal of Public Health, 93, 1386-1389.

Lee, S. M., Wechsler, H., \& Balling, A. (2006). The role of schools in preventing childhood obesity. President's Council on Physical Fitness and Sports, 7(3), 1-8. Retrieved January 22, 2007 from http://fitness.gov/digests/digest-september2006-lo.pdf

Lengerich, E. J., Bohland, J. R., Brown, P. K., Dignan, M. B., Paskett, E. D. Schoenberg, N. E. et al. (2006). Images of Appalachia. Preventing Chronic Disease [serial online]. 3 (4), 1-3. Retrieved December 27, 2006, from http://www.cdc.gov/pcd/issues/2006/oct/06_0064.htm

London, J. K., Zimmerman, K., \& Erbstein, N. (2003). Youth-led research and evaluation: tools for youth, organizational, and community development. New Directions for Evaluation, 98, 33-45.

Lutfiyya, M.N., Lipsky, M.S., Wisdom-Behounek, J., \& Inpanbutr-Martinkus, M. (2007). Is rural residency a risk factor for overweight and obesity for U.S. children? Obesity, 15(9), 2348-2356.

Marcus, B., Forsyth, L. (2003). Motivating people to be physically active. Champaign, IL: Human Kinetics.

McCormack-Brown K., Forthofer, M. S., Bryant, C. A., Eaton, D., Merritt, T., Landis, D. C. et al. (2001). Developing youth capacity for community-based research: The Sarasota County demonstration project. Journal of Public Health Management \& Practice, 7(2), 53-60.

O'Hara Tompkins, N., Rye, J., Zizzi, S., \& Vitullo, E. (2005). Engaging underserved, rural youth in physical activity promotion research in an after school setting. Preventing Chronic Disease, 2 (Special Issue), A15. Retrieved August 27, 2008, from http://www.cdc.gov/pcd/issues/2005/nov/05 0075.htm

Patterson P., Moore C., Probst J., \& Shinogle J. (2004). Obesity and physical inactivity in rural America. Journal of Rural Health, 20(2), 151-159.

Physical Activity Readiness Questionnaire (PAR-Q). (n.d.). Ottawa, ON: Canadian Society for Exercise Physiology. Retrieved August 8, 2006, from http://www.csep.ca/main.cfm?cid=574\&nid=5110

Powell, L. M., Slater, S., Chaloupka, F. J., \& Harper, D. (2006). Availability of physical activity-related facilities and neighborhood and socio-economic characteristics: A national study. American Journal of Public Health, 96, 1676-1680.

Rural population as a percent of state total by state, 2000. (2002, October 24). Retrieved September 11, 2008 from http://www.nemw.org/poprural.htm

Rye, J. (1998). Teacher professional development through an academic enrichment program for underrepresented students in West Virginia. Rural Educator, 19, 7-14.

Rye, J., \& Chester, A. (1999). WVU-community partnership providing science and math enrichment for underrepresented high school students. Academic Medicine, 74, 48-51.

Rye, J., O’Hara Tomkins, N., Eck, R., and Neal, W. (2008). Promoting youth physical activity and healthy weight through schools. West Virginia Medical Journal, 104, 12-15. Retrieved September 8, 2008 from:

http://www.wvsma.com/shared/content_objects/medical journals//mar_apr08mj_web.pdf

Rye, J., Vitullo, E., O'Hara Tompkins, N., \& Zizzi, S. (2006, April). Students' perceptions of their community interventions to increase physical activity opportunities. Poster session presentation at the International Congress for Physical Activity and Health, Atlanta, GA.

Sidman, C., Corbin, C. B., Le Masurier, G. (2004). Promoting physical activity among sedentary women using pedometers. Research Quarterly for Exercise and Sport, 75, 122-129.

The Annie E. Casey Foundation. (n.d.) Kids count census data online. Retrieved September 10, 2008 from http://www.kidscount.org/census

Tolman, J., \& Pittman, K. (2001) Youth acts, community impacts: stories of youth engagement with real results. Community and Youth Development Series, (Vol. 7), Takoma Park, MD: The Forum for Youth Investment, International Youth Foundation.

Tudor-Locke, C., \& Bassett, D. (2004). How many steps/day are enough? Preliminary pedometer indices for public health. Sports Medicine, 34, 1-8.

U.S. Department of Agriculture. (2004). The Child Nutrition and WIC Reauthorization Act of 2004. Retrieved February 2, 2006, from http://teamnutrition.usda.gov/Healthy/108-265.pdf

U.S. Department of Health and Human Services. (1999). Promoting physical activity: a guide for community action. Champaign, IL: Human Kinetics.

U.S. Department of Health and Human Services. (2001). Surgeon General's call to action to prevent and decrease overweight and obesity. Washington, D.C.: U.S. Department of Health and Human Services. Retrieved March 26, 2006, from http://www.surgeongeneral.gov/topics/obesity

Weisstein, E. W. (n.d.) Bonferroni Correction. MathworldA Wolfram web resource. Retrieved July 20, 2006, from http://mathworld.wolfram.com/BonferroniCorrection.ht $\underline{\mathrm{ml}}$ 
West Virginia Department of Health \& Human Services. West Virginia Bureau for Public Health. West Virginia county health profiles. Retrieved September 10, 2008, from

http://www.wvdhhr.org/bph/oehp/hsc/profiles2004/cp0 3d.htm 